\title{
Kritikus infrarenalis aortaszúkület tágítása Bentley BeGraft beültetésével
}

\author{
Olajos Dorottya', Nemes Balázs³, Ruzsa Zoltán ${ }^{1,2}$
}

\author{
'Szegedi Tudományegyetem, Belgyógyászati Klinika, Invazív Kardiológia, Szeged \\ ²Bács-Kiskun Megyei Kórház, a Szent-Györgyi Albert Orvostudományi Egyetem Oktató Kórháza, Kardiológiai \\ Osztály, Invazív Kardiológiai Önálló Részleg, Kecskemét \\ ${ }^{3}$ Semmelweis Egyetem, Szív- és Érsebészeti Klinika, Budapest \\ Levelezési cím: \\ Dr. Ruzsa Zoltán, Szegedi Tudományegyetem, Belgyógyászati Klinika, Invazív Kardiológia, \\ 6725 Szeged, Semmelweis u. 8. E-mail: ruzsa.zoltan@med.u-szeged.hu
}

Az 53 éves nőbeteg bal nagy lábujjgangréna miatt CT-angiográfiás vizsgálaton esik át, amely igazolja a hasi aorta descendens szub-okklúzióját. A szűkület ellátása jobb femoralis és radialis behatolásból történik ballonos előtágítás után két Bentley BeGraft-beültetéssel, szövődménymentesen. A stentgraft-beültetés után a beteg trófikus zavara gyógyul és panaszmentes lesz.

Kulcsszavak: artériás érbetegség, infrarenalis aortastenosis, angioplasztika, stentgraft

\section{Bentley BeGraft stentgraft implantation in infrarenal aortic stenosis}

53 year old female patient with left food critical limb ischaemia underwent CT-angiography investigation. The CT angiography confirmed sub-occlusion of the abdominal aortia. The lesion was treated from femoral and radial artery access with two balloon-expandable Bentley BeGraft successfully, without complication. The wound has been healed after the procedure and the patient remained asymptomatic.

Keywords: arterial vascular disease, infrarenal aortic stenosis, angioplasty, stent graft

\section{Bevezetés}

Az aorta descendens stenosis egy ritka betegség, amely vagy érsebészeti vagy intervenciós megoldással kezelhető. Intervenciós szempontból vagy a ballonos tágítás (1), vagy a stentelés (2-4) alkalmazható kezelés, azonban mindkét kezelésnek a potenciális szövődménye az aortaperforáció, amely egy életveszélyes szövődmény és intervenciós megoldással nagyon nehezen kezelhető. Az aortaszűkület endografttal történő fedése egy alternatív megoldás és ebben az esetben a perforáció esélye alacsony (5-9).

\section{Esetbemutatás}

53 éves magas kardiovaszkuláris rizikójú nőbeteg, aki korábban már hasi aortastenosis miatt hasi aorta ballo- nos angioplasticán (PTA) esett át. Jelen felvételre a bal IV-V. lábujjgangréna miatt került sor. Kórelőzményében szerepel: 2001-ben aorto-bifemoralis bypassmútét, 2016-ban akut bal alsó végtagi iszkémia miatt lokális lízis, majd bal oldali a. iliaca externa és arteria femoralis superfitialis (AFS) PTA, 2017-ben infrarenalis aorta PTA, 2019-ben stroke I.s., 1995-ben cervixkarcinóma miatt opus, radioterápia, 2009-ben ileus miatt opus, 2011ben húgyhólyag-ruptura miatt sutura, urostoma-képzés. 3 hete megjelenő bal IV-V. ujjak gangrénája és nyugalmi bal alsó végtagi fájdalom miatt érsebészeti javaslatra angiológiai kontrollja történt. Vaszkuláris ultrahangon infrarenalis aortaszakaszon szignifikáns, illetve a bal AFS-en kritikus restenosis mutatkozott, ezért első körben aortográfiát és bal AFS gyógyszeres ballonos PTA-t végeztünk, jó angiográfiás eredménnyel. Vascular team véleménye alapján, a redo mútét igen magas rizikójúnak minősült tekintettel a korábbi többszörös hasi műtétre, így 


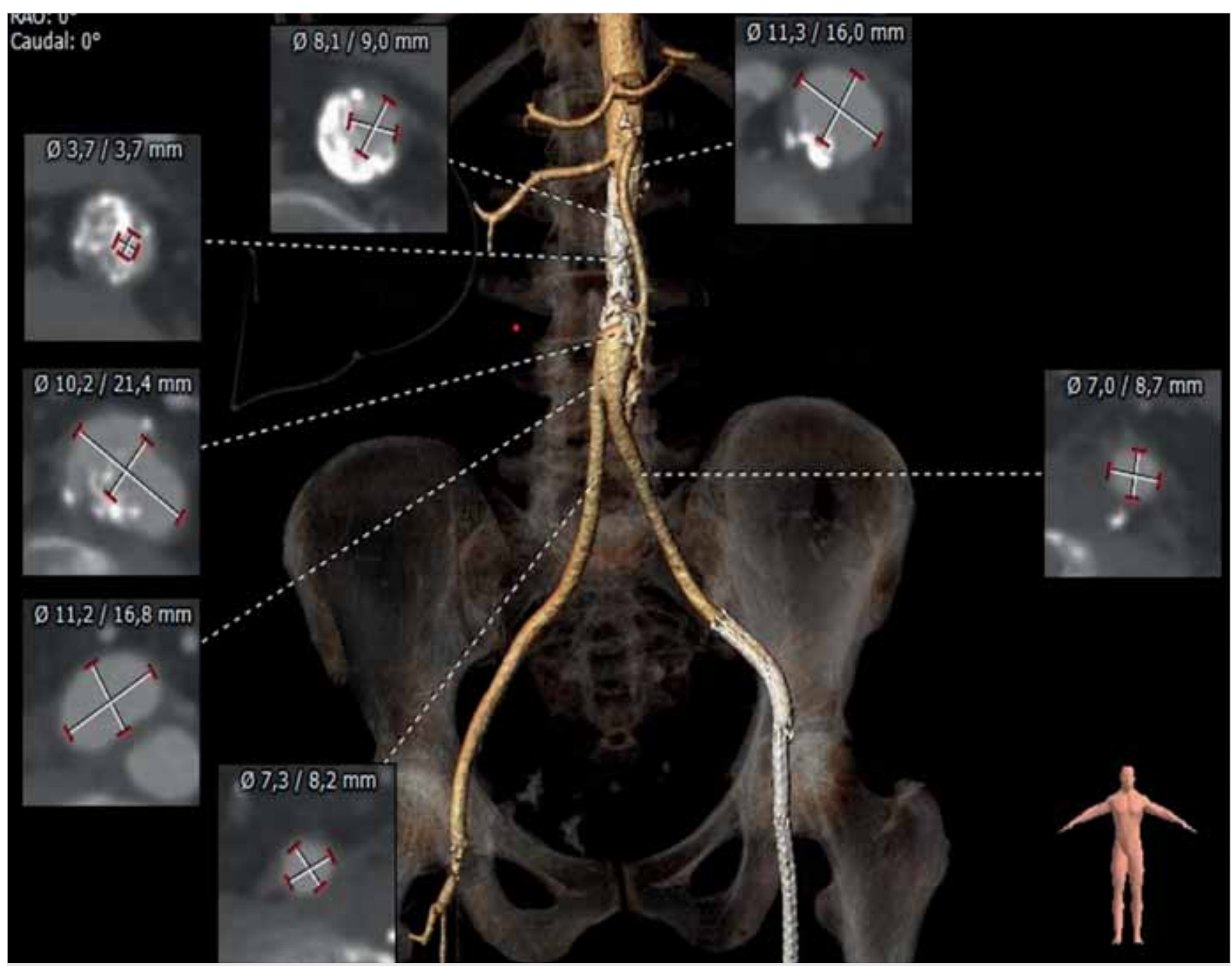

1. ÁBRA. CT-angiográfia és méterezés. A hasi aorta az arteria renalisok alatt kritikus, meszes szűkületet mutat. A CT-angiográfia alapján egy $12 \times 59$ és egy $12 \times 39$ mm-es BeGraft-beültetés jön szóba

PTA mellett döntöttünk. Első lépésben hasi CT-angiográfiás vizsgálattal rekonstruáltuk az aorta és a nagyerek lefutását méreteztük a stentgraftot a szükületnek megfelelően és megjelöltük a szúrás helyét (1. ábra). Második lépésben intervenciót végeztünk. Előkészítést követően bal distalis arteria radialis behatolásból (6F sheat) egy 125 cm-es Pigtail-katétert vezettünk az aortába. Ultrahangvezérelt arteria femoralis communis szúrás után a szűkületen keresztül egy Terumo dróttal (Terumo) átmentünk, majd ballonos előtágítást végeztünk (Advance 35 $8 \times 60$, Abbot, USA) egy Jindo dróton (Cordis) keresztül. A szükületet egy 12×39 mm-es és egy 12×59 mm-es Bentley BeGraft-tal fedtük le (Bentley, USA), jó angiográfiás eredményt elérve. A femoralis behatolást 8F-es Angioseal-lel zártuk (Abbot, USA). A szúrás helyén további szivárgó vérzést észleltünk, ezért a bal distalis arteria radialis felöl ballonos tágítást végeztünk a femoralis punkció helyén, jó eredménnyel. Beavatkozást követően mérsékelt fokú anemizálódás miatt az érsérülés kizárására célzott ultrahangvizsgálatot végeztünk. Vaszkuláris szövődmény nem igazolódott. $A$ beteg a beavatkozás után
6 hónapig kettős thrombocyta anti-aggregációs kezelést kapott. 6 hónapos kontrollra sebei meggyógyultak, járástávolsága megnőtt (DT: 200 m).

\section{Megbeszélés}

Az aorta descendens szükületek ellátása történhet tradicionális sebészi úton aorto-bifemoralis bypass biztosításával, vagy endovaszkuláris módszerrel PTA-val vagy aortastenteléssel. A PTA lehetséges szövődményei az aortadisszekció, -elzáródás és -perforáció. A Odurny és munkatársai 25 infrarenalis aortastenosisos beteg adatait publikálták. A PTA során nem volt vaszkuláris komplikáció és az 5 éves nyomonkövetés során a nyitvamaradás $70 \%$-os volt. A aorta primer stentelése már a sebészi eljárásokkal összehasonlítható eredményeket mutat. U Nyman és munkatársai 30 betegben végeztek primer stentelést 93\%-os sikerrátával. Egy betegben észleltek restenosist a 26 túlélő betegből egyéves kontroll során (3). A fő szövődmények a be- 


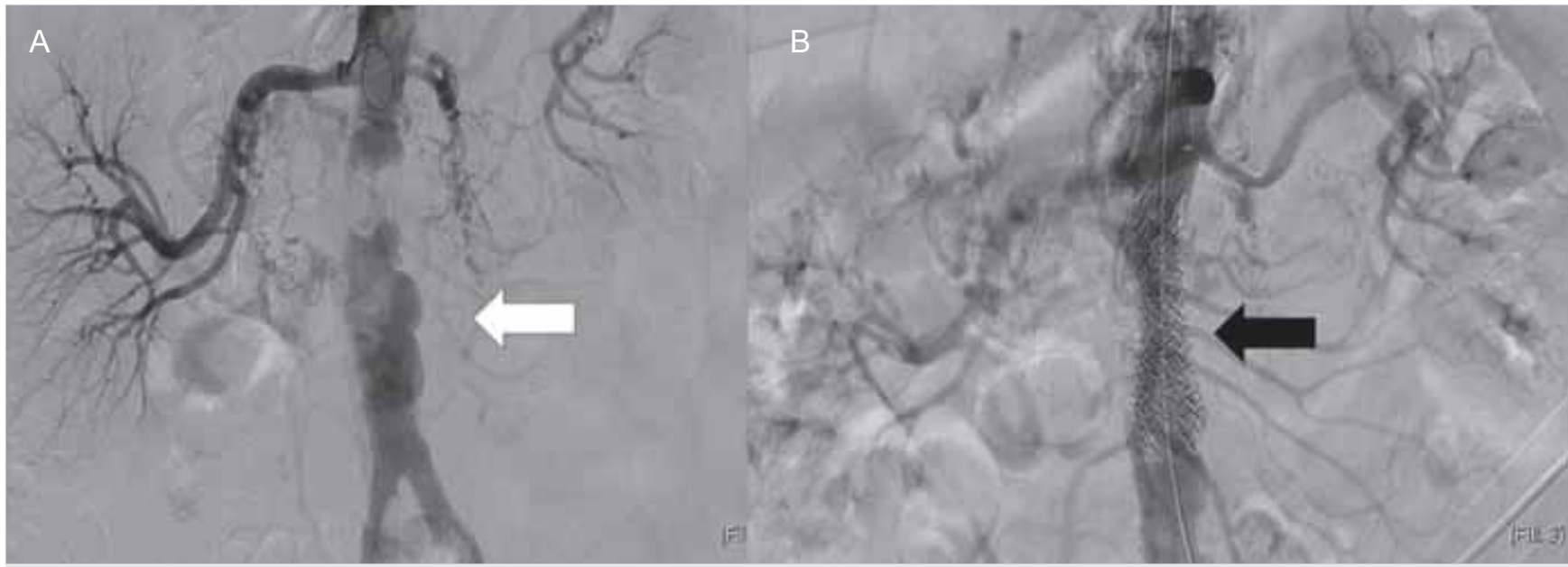

2. ÁBRA. Abdominalis DSA-vizsgálat. A ÁBRA. Jobb arteria radialis behatolásból végzett DSA-vizsgálat igazolja az aorta descendens szub-okklúziót (fehér nyíl). Nyomásgrádiens $75 \mathrm{Hgmm}$ a beavatkozás előtt. B ÁBRA. Záró angiográfia radialis behatolásból jó angiográfiás eredményt mutat. Nyomásgrádiens 5 Hgmm a beavatkozás után

avatkozás alatt egy betegben a major haematoma, egy betegben miokardiális infarktus, két distalis embolizáció (egy halál és egy agyvérzés lízis miatt). Simons és munkatársai 27 hónapos nyomonkövetés során 2 betegben észleltek instent restenosist (11,7\%). A ballonra applikált stentgraftok tovább csökkenthetik a procedurális szövődmények előfordulását a beavatkozás alatti perforáció és a distalis embolizáció rizikójának csökkentésével, illetve esetlegesen a hosszú távú nyitva maradás biztosításával. A stentgraftok eredményesen csökkentik a procedurális szövődmények előfordulását és hosszú távú nyitva maradást arteria iliaca communis intervenciók során (5). A DISCOVER-studyban balIon expandibilis fedett és nem fedett stenteket (Advanta $\mathrm{V}_{12}$, Atrium Medical Inc., Hudson, NH, USA) hasonlítja össze arteria iliaca communis intervenciója során, de a betegbevonás még folyik. Egy jelenleg publikált metaanalízis során az arteria iliaca intervenciók során használt stentgraftok (iCast/Advanta $V_{12}$, Viabahn VBX, BeGraft, LifeStream, and JOSTENT) egy évesen csökkentik mind a reintervenció számot és emelik a technikai sikerrátát. Hosszú távú eredményei az iCast/ Advanta $V_{12}$ stentnek van. Ennek a stentnek a nyitva maradása 5 évesen 75\% (6). A BeGraft Bentley stent egy ballon expandibilis perifériás stentgraft, amelyet főleg aorta és iliaca sérülés esetén, felnőttkori coarcatiók esetén használják $(7,8)$. A stent fő előnye az alacsony profil, a jó felvezethetőség, a jó láthatóság, a jó után tágíthatóság és a pontos elhelyezés lehetősége. Aortaaneurizma szűkületek ellátására való alkalmazhatóságára a FEVAR-study folyamatban van (9).

\section{Következtetések}

Érsebészeti szempontból magas műtéti rizikójúnak nyilvánított betegekben a hasi aortaszűkületek gondos ter- vezést követően percutan intervenciós megoldással jól kezelhetők alacsony intervenciós rizikó mellett.

\section{Nyilatkozat}

A szerzők kijelentik, hogy az esetismertetés megírásával kapcsolatban nem áll fenn velük szemben pénzügyi vagy egyéb lényeges összeütközés, öszszeférhetetlenségi ok, amely befolyásolhatja a közleményben bemutatott eredményeket, az abból levont következtetéseket vagy azok értelmezését.

\section{Irodalom}

1. Grollman JH, Del Vicario M, Mittal AK. Percutaneous transluminal abdominal aortic angioplasty. AJR 1980; 134: 1053-1054.

2. Odurny A, Colapinto RF, Sniderman KW, et al. Percutaneous transluminal angioplasty of abdominal aortic stenoses. Cardiovasc Intervent Radiol 1989; 12 1-6.

3. Nyman U, Uher P, Lindh M, Lindblad B, Ivancev K. Primary stenting in infrarenal aortic occlusive disease. Cardiovasc Intervent Radiol 2000 Mar-Apr; 23(2): 97-108.

4. Simons PC, Nawijn AA, Bruijninckx CM, Knippenberg B, de Vries $\mathrm{EH}$, van Overhagen $\mathrm{H}$. Long-term results of primary stent placement to treat infrarenal aortic stenosis. Eur J Vasc Endovasc Surg 2006 Dec; 32(6): 627-33. Epub 2006 Jul 21

https://doi.org/10.1016/j.ejvs.2006.05.010

5. Bekken JA, Vos JA, Aarts RA, de Vries JP, Fioole B. DISCOVER: Dutch Iliac Stent trial: COVERed balloon-expandable versus uncovered balloon-expandable stents in the common iliac artery: study protocol for a randomized controlled trial. Trials 2012 Nov 19; 13: 215

6. B. Patrice Mwipatayi, Kenneth Ouriel, Tahmina Anwari, Jackie Wong, Eric Ducasse, Jean M. Panneton, Jean-Paul P.M. de Vries, Rajesh Dave. A systematic review of covered balloon-expandable stents for treating aortoiliac occlusive disease. Journal of Vascular Surgery Volume 2020; 72(4): 1473-1486.e2.

7. Ruffino MA, Fronda M, Varello $S$, et al. Emergency management of iatrogenic arterial injuries with a low-profile balloon-expandable stent-graft: Preliminary results. Medicine 2020 April; 99(15): e19655 8. Promphan W, Han Siang K, Prachasilchai P, et al. Feasibility and early outcomes of aortic coarctation treatments with BeGraft Aortic stent. Catheter Cardiovasc Interv 2020 Sep 1; 96(3): E310-E316.

9. Verhoeven EL, Katsargyris A, Oikonomou K, et al. Fenestrated endovascular aortic aneurysm repair as a first line treatment option to treat short necked, juxtarenal and suprarenal aneurysms. Eur J Vasc Endovasc Surg 2016; 51(6): 536-42. 